\title{
A história paralela contada pelos motion graphic designers em aberturas
}

\author{
The parallel story told by motion graphic designers in opening titles
}

Jaíne Cintra, Paulo Carneiro da Cunha Filho e Marcelo Soares

créditos de abertura, motion graphic design, Michael Betancourt

Este artigo fala da relação entre o texto e a imagem em aberturas. O que começou no cinema nos anos 1950, migrou para séries, telenovelas e games. Vamos apresentar a teoria proposta no livro Semiotics and title sequences -Text-Image Composites in Motion Graphics, de Michael Betancourt (Routledge, 2017), a partir de uma resenha do autor referenciado. Para identificarmos trabalhos que tenham similaridade com a teoria do autor, utilizamos as etapas sugeridas pela ferramenta StarT para uma Revisão sistemática de literatura: Planejamento, Execução, Seleção e Extração. Assim, apresentaremos uma análise retórica própria para estas narrativas, proposta no lugar das abordagens que consideram estes trabalhos apenas como apêndices das produções principais que acompanham e suas três características principais: o modo Imagem como base, o Caligrama e o modo Rébus.

opening credits, motion graphic design, Michael Betancourt

This article talks about the relationship between text and image in openings. What started in the cinema in the 1950s, migrated to series, soap operas and games. We will present the theory proposed in the book Semiotics and title sequences - Text-Image Composites in Motion Graphics, by Michael Betancourt (Routledge, 2017), from a review of the referenced author. To identify works that have similarity with the author's theory, we use the steps suggested by the StarT tool to perform a systematic literature review: Planning, Execution, Selection and Extraction. Thus, we will present our own rhetorical analysis for these narratives, proposed in place of the approaches that consider these works only as appendages of the main productions they accompany and their three main characteristics: the Image-as-Base mode, the Calligram and the Rébus mode.

\section{Introdução}

Dar nome a tradições técnicas ou estéticas é uma etapa importante para produzir teoria em áreas que carecem de aprofundamentos mais robustos. Foi o que Michael Betancourt se propôs a fazer no livro Semiotics and title sequences - Text-Image Composites in Motion Graphics (Routledge, 2017). O autor considera como o texto e a imagem se combinam para trazer significados nas aberturas em três categorias: The Figure-Ground mode (o modo Imagem como base), the Calligram mode (o modo Caligrama) e the Rebus mode (o modo Rébus).

Mesmo sendo uma narrativa incorporada aos filmes nos Estados Unidos pelo menos desde os anos 1950, ainda faltam análises mais densas na área do motion graphic design para

Anais do $10^{\circ} \mathrm{CIDI}$ e $10^{\circ} \mathrm{CONGIC}$

Kelli C.A.S. Smythe, Rafael de Castro Andrade (orgs.)

Sociedade Brasileira de Design da Informação - SBDI

Curitiba | Brasil | 2021
Proceedings of the $10^{\text {th }} \mathrm{CIDI}$ and $10^{\text {th }}$ CONGIC

Kelli C.A.S. Smythe, Rafael de Castro Andrade (orgs.)

Sociedade Brasileira de Design da Informação - SBDI Curitiba | Brazil | 2021 
aberturas na forma como conhecemos hoje. Na teoria do cinema, muitas destas análises se concentram apenas na relação ideal entre a abertura e a narrativa do filme, em vez de desenvolver quaisquer teorias gerais próprias para o seu design ou pensamento. Boa parte dos estudos hoje segue as tradições do design gráfico, permanecem na apresentação dos modelos ou autores que se destacam nas suas áreas.

Muitas terminologias são usadas para identificar a área: opening titles ou title sequence, motion graphic, motion graphic design, title design ou broadcast design. No Brasil, por exemplo, há o termo videografismo. O uso do termo motion graphic, apesar de bastante popular para denominar a profissão, em alguns momentos, faz parecer que a atividade significa mover elementos, por sua vez, o title design relaciona-se muitas vezes com quem coloca os créditos e o broadcast design é usado para os profissionais que trabalham em estúdios de TV, fazendo identidade visual ou até mesmo a abertura, por exemplo. Neste artigo, optamos pelo termo motion graphic design ou abertura, pela popularidade atual e por compreendermos que a atuação desse profissional é mais ampla e abrange outras questões narrativas para além do movimento ou da aplicação do crédito. Sendo assim, é mais coerente com o pensamento sistêmico que acontece na elaboração dos trabalhos. Portanto, vamos apresentar um breve contexto histórico de atuação destas narrativas e quais as características mais comuns da relação entre o texto e a imagem: Imagem como base, Caligrama e Rébus.

\section{De Saul Bass às plataformas de streaming}

Saul Bass, cujo centenário de nascimento foi comemorado em 2020, foi o designer responsável por aposentar as cortinas no cinema. Antes dos seus trabalhos, as aberturas eram projetadas acima das cortinas ainda fechadas, que só abriam para a plateia no início do filme. As sessões começavam com as luzes lentamente sendo apagadas e a cortina vagarosamente recolhida (Augusto, 2020). O cineasta Otto Premiger, no filme Man With The Golden Arm (O homem do braço de ouro, 1955), Figura 1, colou uma nota nos rolos do filme que alertava: 'Projecionistas, puxem a cortina antes da abertura', exatamente por perceber que o trabalho realizado por Bass era mais do que apenas subserviente ao filme, tinha vida própria, apesar de só existir por conta da produção que ele acompanhava. Sobre sua trajetória, Saul Bass comentou:

[...] eu comecei a pensar sobre o que fazer no início de um filme. Obviamente o objetivo de qualquer crédito de abertura é apoiar a película. Meus pensamentos iniciais sobre o que um crédito de abertura poderia fazer era definir o humor e preparar o núcleo fundamental da história do filme; para expressar a história de alguma maneira metafórica. Via o crédito de abertura como uma forma de condicionar o público, então quando o filme começasse, os espectadores já teriam uma ressonância emocional com ele (apud HASKIN, 1996, p.12, tradução nossa). 
Figura 1: Frames da Man with the golden arm, 1955. Fonte: YouTube
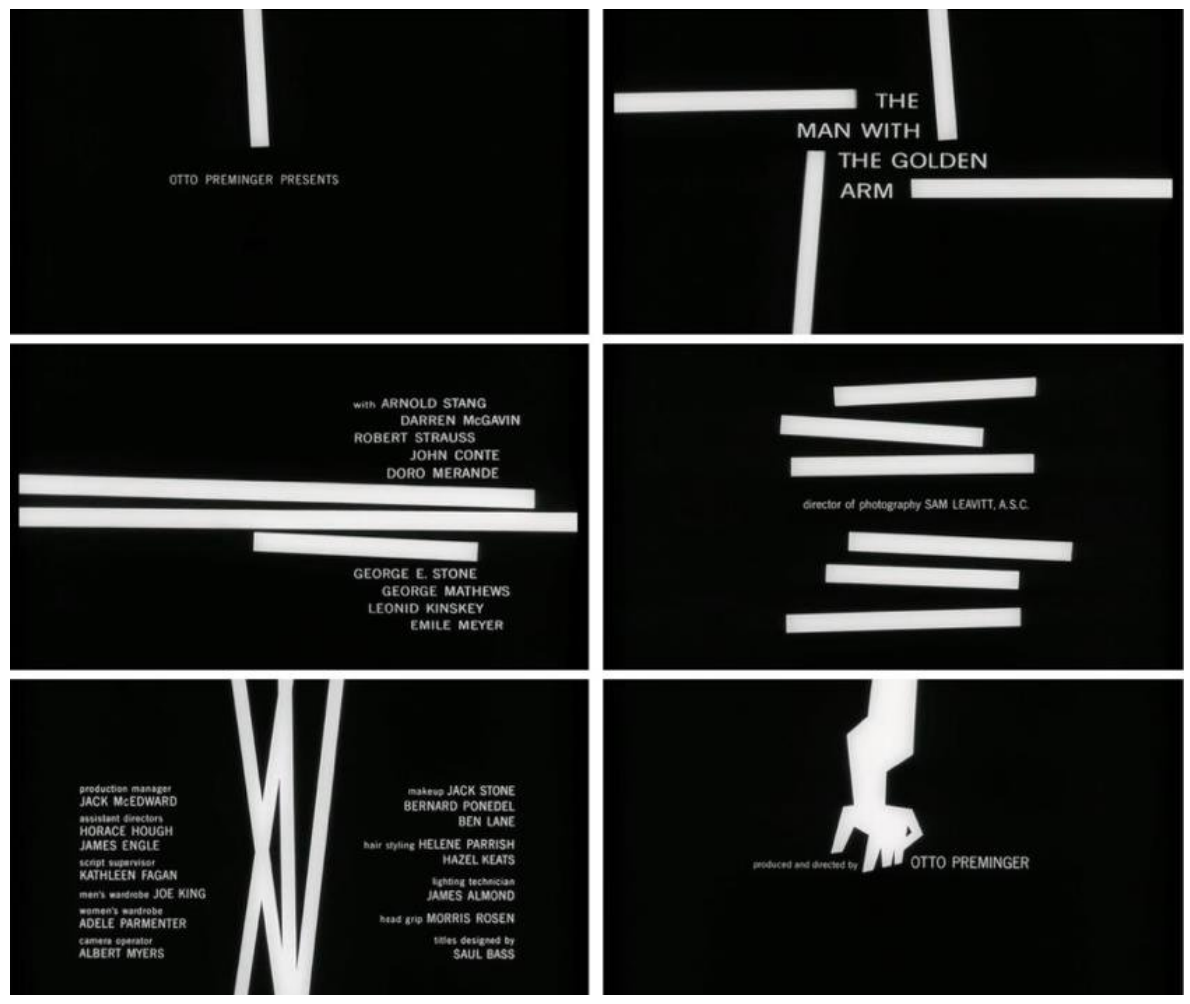

O filme The Jazz Singer (1927), é um dos raros exemplos em que o designer da abertura foi creditado antes do sucesso de Saul Bass: Jack Jarmuth. Segundo Michael Betancourt, em 1934, os créditos dos designers desapareceram e só retornaram com Bass nos filmes Carmen Jones (1954) e The Man With the Golden Arm (O homem do braço de ouro, 1955). Com esses designers sendo creditados novamente nos projetos, não só houve um marco temporal de uma nova linguagem se estabelecendo como também se instituiu o reconhecimento da profissão.

Até então, muito do que era produzido não recebia autoria por parte das empresas especialistas que atendiam ao mercado cinematográfico.

É interessante como a definição de Bass acima remonta à forma clássica da atuação das aberturas: no início, subserviente ao filme e ao mesmo tempo independente dele. Um papel controverso até hoje, porque embora os créditos e outros nomes que aparecem só existam por causa do filme, série, telenovela ou outro produto ao qual estão anexados, a linguagem visual dessas produções, muitas vezes, é totalmente independente do que será exibido. A abertura da série Mad Men (2007) é um exemplo de como estes trabalhos muitas vezes sobrevivem à trama, ganhando releituras por outras produções e tendo vida própria para além do conteúdo que acompanha (Figura 2). 
Figura 2: À direita, frame da abertura feita pelo estúdio Imaginary forces para série Mad Men (2007). À esquerda, releitura para a $25^{\mathrm{a}}$ temporada dos Simpsons em 2014. Fonte: YouTube
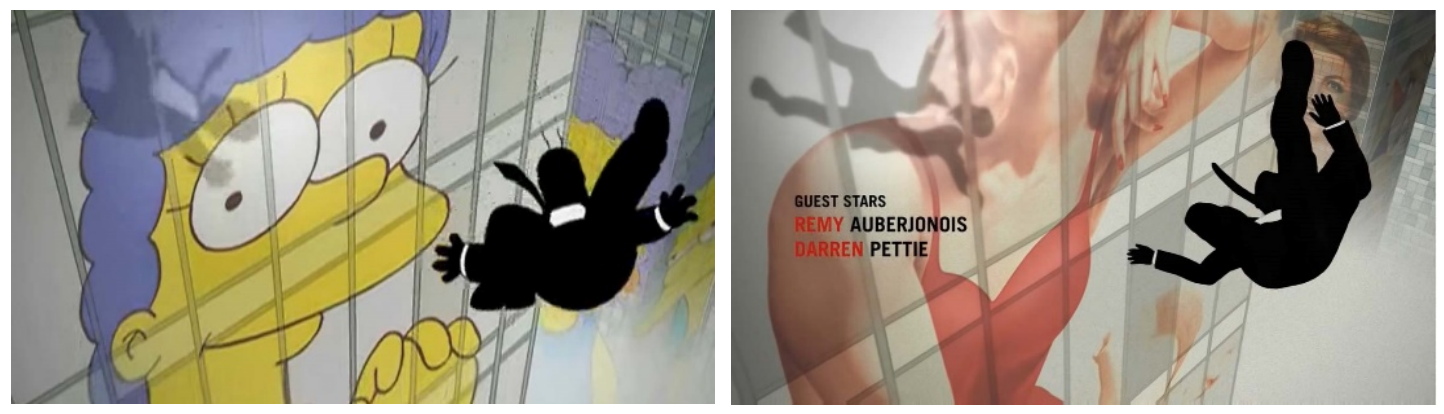

Em 2017, houve um caso que mostra como as aberturas de filmes e séries assumiram, de forma mais clara, autonomia das produções introduzidas por elas. A plataforma de streaming Netflix estreou seu botão "Pular abertura" (Skip Intro). O recurso levantou uma polêmica: estúdios como a Imaginary Forces, fundado em 1996 pelo designer Kyler Cooper e um dos mais influentes da história moderna do motion graphic design, protestou com a hashtag \#DontSkipTheTitles (\#nãopulemasaberturas). Rapidamente, muitos espectadores apoiaram a ideia nas redes sociais por concordarem que essas narrativas enriquecem o contexto fílmico. Numa atualização do que foi iniciado nos anos 1950, a introdução dessa linguagem para a TV, plataformas de streaming ou mesmo as aberturas de games trouxeram trabalhos que interagiam com os telespectadores e com a sua relação com o programa ou filme em algum nível. Aberturas que mudam de acordo com a temporada ou aquelas que satirizam questões internas da série tornaram-se comuns. Mais do que demarcar o início, estes trabalhos têm autonomia e contam de forma sucinta uma história paralela e pertencente à trama que acompanham.

\section{Metodologia}

A revisão bibliográfica percorreu diversos tipos de análises de aberturas de obras distintas. Publicações lançadas desde o ano 2017 até o ano 2021 foram levantadas a fim de criarmos um cenário que contemplasse a avaliação dessa narrativa em sua totalidade e não apenas a partir da relação com a obra que as acompanha ou da autoria do designer. Logo, essa etapa permitiu não só uma compreensão histórica da análise de aberturas, mas também contextualizou a importância desses trabalhos no cinema, na TV e na web.

Um Protocolo de Revisão Sistemática da Literatura (PRSL) foi planejado para a execução da etapa de revisão, a partir da pergunta principal da pesquisa: "Podemos classificar as relações existentes entre o texto e a imagem em aberturas de filmes, novelas ou seriados?". A pergunta de pesquisa desta Revisão Sistemática de Literatura (RSL) é derivada da definição dos elementos apresentados na Tabela1: 
Tabela 1: Descrição dos Critérios da Pesquisa

\begin{tabular}{ll}
\hline Critérios & Descrição \\
\hline População & Produções científicas sobre title sequence design ou motion graphic design \\
Intervenção & Leitura e separação de classificação dos créditos em aberturas \\
Controle & $\begin{array}{l}\text { Artigos com a teoria proposta por Michael Betancourt para o title sequence } \\
\text { design }\end{array}$ \\
Resultado & Artigos que avaliem a classificação do texto e da imagem em aberturas \\
Contexto & Relações entre créditos e imagens para produzir outros significados \\
\hline
\end{tabular}

As bases de dados Google Acadêmico e Web of Science foram consultadas a fim de levantarmos artigos, teses, dissertações e periódicos que ampliassem a teoria do autor lançada em 2017. Este processo de busca foi formado pela string genérica apresentada na Tabela 2.

Tabela 2: String Genérica de Busca

\begin{tabular}{ll}
\hline $\begin{array}{l}\text { String } \\
\text { genérica }\end{array}$ & ("title sequence design" OR "Michael Betancourt”) AND Motion graphic design \\
\hline
\end{tabular}

Para as bases de dados selecionadas, adaptamos a string a cada banco de dados e encontramos os resultados preliminares explicitados na Tabela 3.

Tabela 3: Termos de Busca

\begin{tabular}{|c|c|c|}
\hline Base de dados & Srting adaptada/utilizada & Resultados \\
\hline Google Acadêmico & $\begin{array}{l}\text { ("title sequence" OR "Michael } \\
\text { Betancourt") AND motion graphic } \\
\text { design AND title designs, AND } \\
\text { ("opening title" OR "Michael } \\
\text { Betancourt") }\end{array}$ & 32 \\
\hline Web of Science & $\begin{array}{l}\text { Title sequence OR Michael } \\
\text { Betancourt or opening title or } \\
\text { motion graphic design }\end{array}$ & 30 \\
\hline
\end{tabular}

Os resultados encontrados foram levados à ferramenta StarT em formato BIBtex, a fim de que cumprissem as quatro etapas sugeridas pelo software: Planejamento, Execução, Seleção e Extração. Textos duplicados ou incoerentes com o nosso Critério de Inclusão, Tabela 4, foram excluídos. 
Tabela 4: Critérios de Inclusão

\begin{tabular}{ll}
\hline Critérios & Descrição do Critério de Inclusão \\
\hline $\mathrm{Cl} 1$ & $\begin{array}{l}\text { Serão incluídos textos que tratem do motion graphic, title sequence design ou } \\
\text { opening title.como trabalhos que por si só geram teorias, sem necessidade da } \\
\text { análise da obra ao qual está anexado }\end{array}$ \\
$\mathrm{Cl} 2$ & $\begin{array}{l}\text { Serão incluídos trabalhos publicados e disponíveis integralmente nas bases } \\
\text { científicas buscadas. }\end{array}$ \\
$\mathrm{Cl} 3$ & Serão incluídos trabalhos que referenciem a teoria de Michael Betancourt. \\
\hline
\end{tabular}

Na etapa de Seleção, foi executada a análise dos títulos de cada um dos estudos, descartando aqueles que claramente não estavam relacionados à estratégia de busca, ou que não preenchiam os Critérios de Inclusão, Critérios de Qualidade, Tabela 5, ou estejam relacionados aos Critérios de Exclusão, Tabela 6, definidos.

Tabela 5: Critérios de Qualidade

\begin{tabular}{ll}
\hline Critério & Descrição do Critério de Qualidade \\
\hline CQ1 & O artigo foi escrito com coerência e coesão textual? \\
CQ2 & A utilização da classificação de Betancourt foi usada ou referenciada? \\
\hline
\end{tabular}

Tabela 6: Critérios de Exclusão

\begin{tabular}{ll}
\hline Critérios & Descrição do critério de exclusão \\
\hline CE1 & $\begin{array}{l}\text { Serão excluídos os trabalhos que não analisem o title sequence design ou } \\
\text { motion graphic design como narrativas próprias }\end{array}$ \\
CE2 & Serão excluídos trabalhos que não foram publicados depois de 2017. \\
CE3 & Serão excluídos trabalhos que não apresentem resumo/abstract. \\
\hline
\end{tabular}

No total, 17 publicações atenderam nossos Critérios de Inclusão a partir do título ou resumo/abstract, conforme mostra a visualização radial da Figura 3. 
Figura 3: Visualização radial das publicações selecionadas fornecida pela ferramenta StarT.

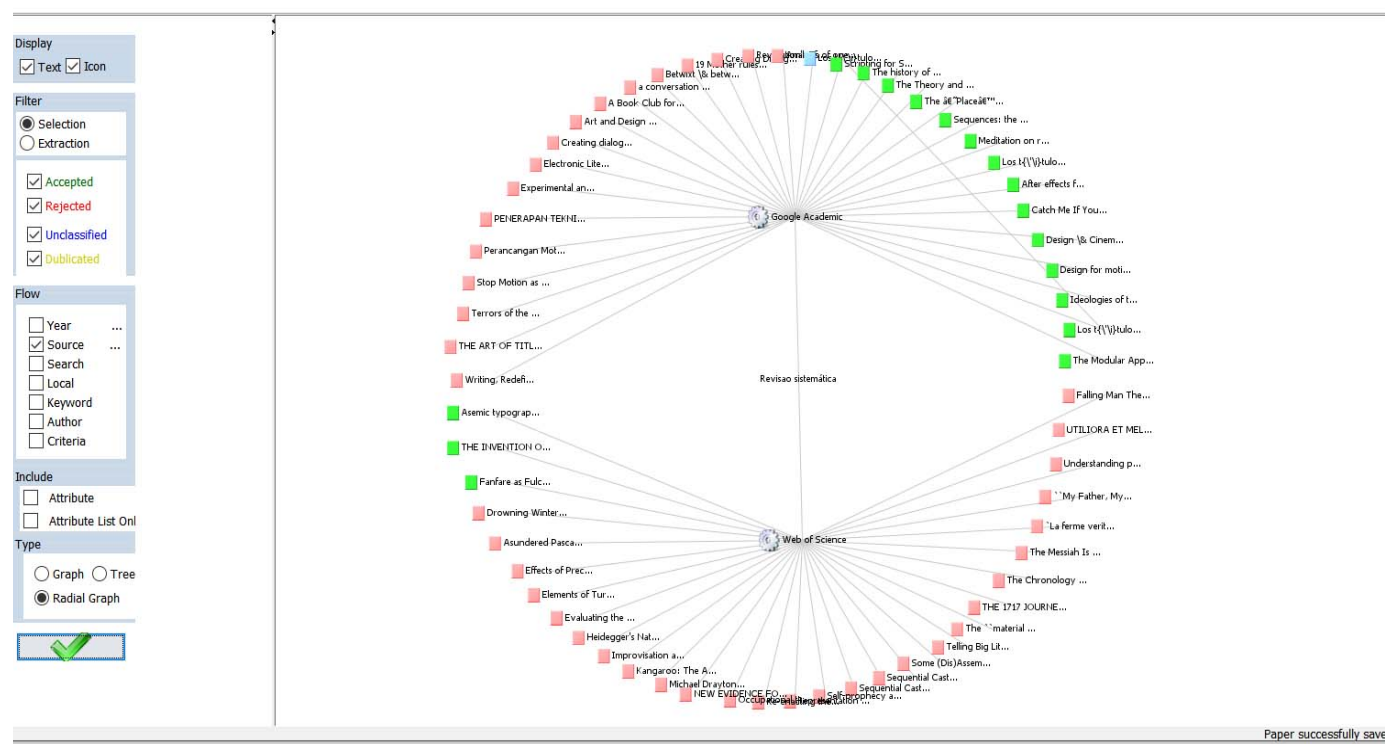

$\mathrm{Na}$ etapa de Extração, 13 leituras foram escolhidas, conforme mostra a Figura 4 e a partir dessas análises, fomos limitando os textos que dialogavam com nosso interesse.

Figura 4: Visualização radial das publicações selecionadas fornecida pela ferramenta StarT.

\section{Extraction}

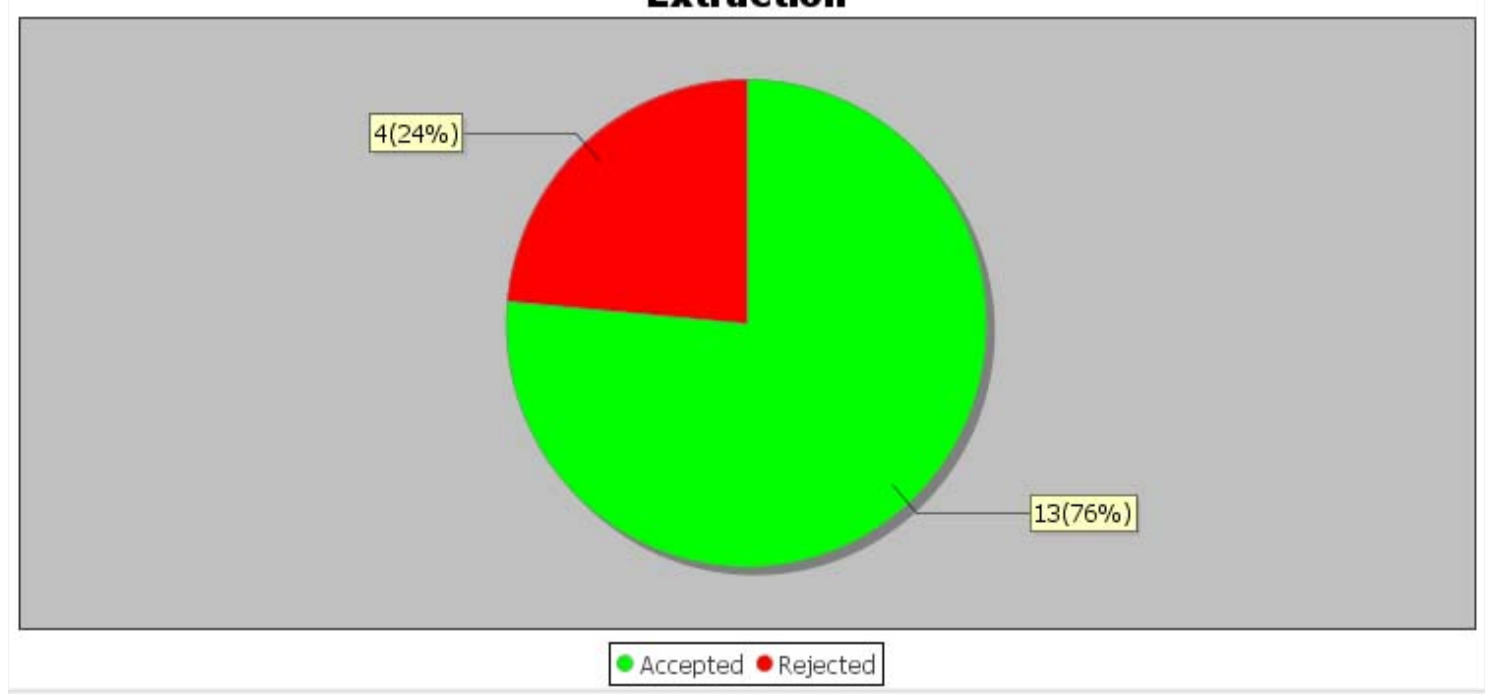

Após finalizada a extração dos dados, analisamos, interpretamos e documentamos os resultados para obtermos o relatório da Revisão Sistemática fornecida pela ferramenta e catalogamos nossos achados para buscas futuras, apesar de avaliados, não significa que usamos todos os 13 achados para a criação deste estudo, fizemos uma escolha por similaridade de objetivo. Destacamos dois trabalhos que tratam das aberturas ou do motion graphic design como significantes por si só: o trabalho Design \& televisualidades (ou, das formas videográficas), de Milena Szafir, verificou a potência do motion graphic design como parte estética de uma obra. Avaliou especificamente três episódios da série Black Mirror (2011 
- 2014, Netflix) e sua construção imagética para um debate estético. O segundo trabalho, uma resenha feita sobre o livro 'Can you make a title?': Interview with Saul (Haskin, 1996), intitulada Saul Bass: uma anatomia do design de filmes (Bicalho, 2017), apresenta como os trabalhos de Saul Bass (1920-1996) ultrapassaram a obra em si que acompanhavam e criaram significação própria ao longo de sua trajetória.

\section{Discussão}

A teoria proposta por Betancourt diz respeito à organização do texto relação à imagem em que ele se apoia - de maneira direta ou retórica, assim entendido quando há a exigência de outros conhecimentos por parte do espectador. A abertura, uma composição híbrida de texto, imagem e som, é considerada pelo autor de fato uma abertura quando há a união entre imagem e texto, em movimento ou não. O som, apesar de normalmente fazer parte desse contexto, não é imprescindível. Como exemplo, aponta a série de televisão Castle (2009-2016), produzida pelo canal americano ABC. Nela, a logomarca aparece sem que os nomes dos participantes da equipe sejam exibidos nas imagens anteriores. Mesmo neste caso, a presença da logomarca (o texto) é suficiente para que ela seja enquadrada como abertura. (Figura 5).

Figura 5: Frame da série Castle (2009-2016). Fonte: YouTube

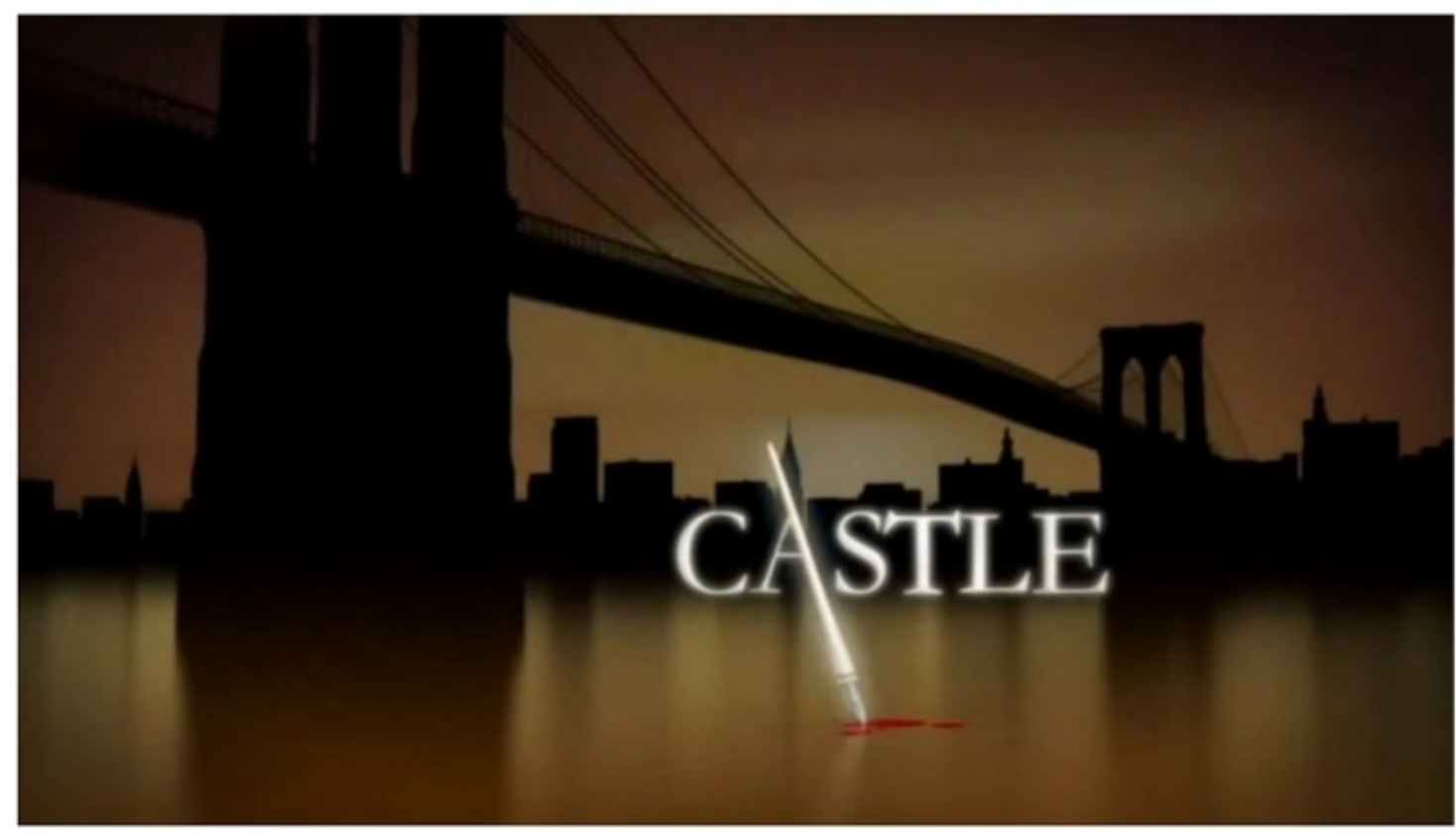

Esta classificação específica do comportamento do texto e da imagem em aberturas surgiu pelo baixo índice de teorias próprias para estas narrativas. Betancourt aponta como as análises tentam dar princípios gerais e abstratos do design a partir de exemplos catalogados e observa que tal consideração leva a uma identificação dos modelos a serem imitados. A análise a partir da forma é uma ação científica que captura "borboletas raras" para que estudos posteriores possam iniciar pesquisas sobre o tema. No entanto, o design não é uma "borboleta", é um 
produto cultural que atende a fins específicos e significativos, produzido por seres humanos, e que não deriva de algum processo natural autônomo.

O caminho utilizado por Michael, da semiótica e da retórica, está em confluência com outros estudiosos atuais do tema (Lupton, 2020; Leão, 2013) e se destaca porque não pretende analisar um grupo pela taxonomia ou por agrupamento. $\mathrm{O}$ autor propõe mais do que a simples comparação entre os grandes nomes da área, a exemplo de Pablo Ferro, Saul Bass, e Kyle Cooper. Incentiva a análise de cada caso individualmente - a partir da narrativa e, sobretudo, da construção autônoma e independente do trabalho.

A tipografia sobre imagens é uma parte comum do design gráfico e, consequentemente, do motion graphic design. A colocação do texto sobre uma imagem de fundo - animado ou não é uma etapa recorrente em filmes, séries de televisão e games. A organização gráfica da tela, no entanto, não é tão monótona quanto essa singularidade técnica pode implicar.

Como o público entende a relação entre a tipografia (em primeiro plano) e a imagem (em segundo plano) coloca em questão uma sequência de outras dinâmicas mais gramaticais da leitura. Neste livro, são exatamente estes tipos de percepções que geram os modos Imagem como base, Caligrama e Rébus, usados pelo autor como ponto de partida para as análises.

Se o reconhecimento mais básico dessas composições invoca a relação direta de um texto ligado a uma imagem, teremos um Caligrama. Se afirma a independência de elementos que não têm uma conexão imediata, teremos o modo Imagem como base. Já a relação descrita pelo modo Rébus depende de reconhecimentos de níveis mais complexos, da retórica implementada e são separados do que é imediatamente aparente.

\section{O modo Imagem como base}

É, historicamente, a organização mais comum de imagem e texto nas aberturas: o texto ocupa um 'campo' dentro do quadro e as outras imagens caem no 'plano de fundo'. A separação entre texto e imagem é imediatamente aparente. Um não é ilustração do outro, são duas partes separadas e independentes do design que aparecem juntas na tela. A falta de correlação direta significa que o desenvolvimento e o significado das imagens em fundo progridem sem preocupação com o que o texto pode declarar.

A figura abaixo mostra uma relação alusiva entre a imagem de fundo e o texto sobreposto as sombras femininas vestem roupas de aparência espanhola e se movem pela tela de uma maneira que sugere a dança, o filme é intitulado Rumba". Esta ligação funciona para o título do filme em si, mas não é uma conexão refletida nos demais créditos exibidos (Figura 6). 
Figura 6: Frames da abertura do filme Rumba, 1935. Fonte: Michael Betancourt

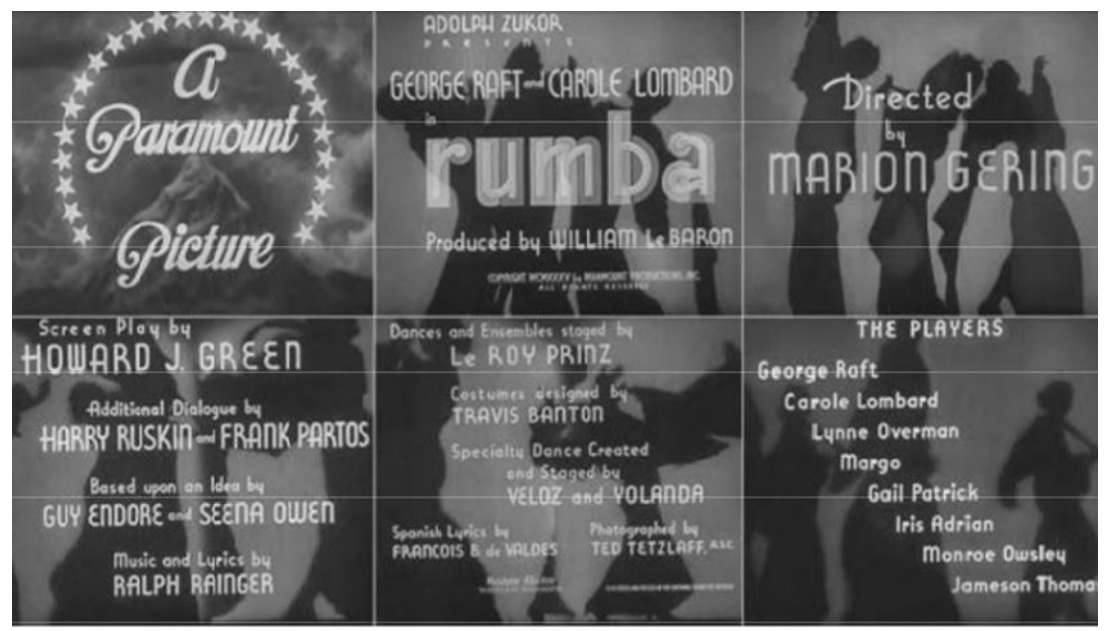

O modo Imagem como base emprega demarcações claras entre leitura e visão. O texto e a imagem permanecem distintos, independentes um do outro: são áreas separadas que não têm relação imediatamente aparente, nem implicam uma conexão. Sobre isto, o autor não vê diferença interpretativa significativa entre uma cartela de título que emprega o modo Imagem como base feito em 1935 de um feito quase setenta e cinco anos depois em 2011, Unknown (Desconhecido), de 2011 (Figura 7).

Figura 7: Frame da abertura de Unknown (desconhecido), 2011. Fonte: YouTube

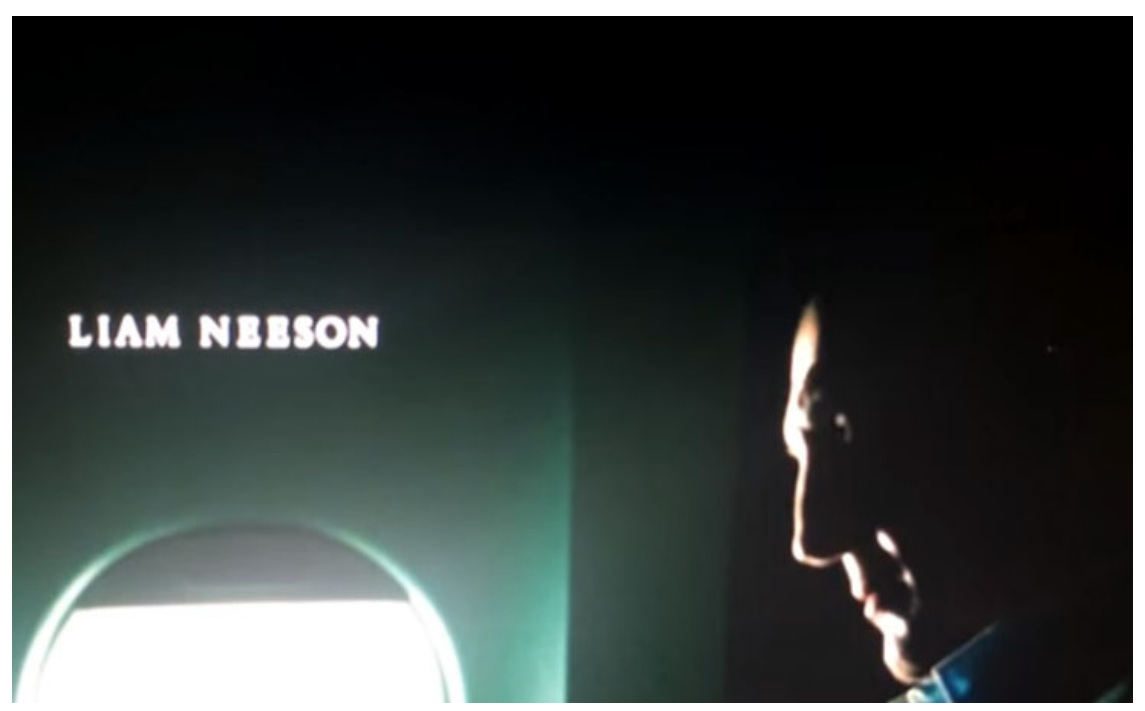

Porém, na abertura de Unknown (Desconhecido, 2011), apesar de também pertencer ao modo Imagem como base, estas relações ganham outro significado. Em vez de vez de aparecer em um fundo qualquer fornecido como acessório para o texto, a sequência de créditos é integrada às cenas iniciais do filme. A tipografia é secundária às atividades dramatizadas na tela. Ignorar o texto e focar na imagem de "fundo" não é apenas apropriado, é esperado. $\mathrm{O}$ drama e seu desdobramento na tela tornam os textos secundários.

Permanecendo em seus próprios campos, o texto e a imagem entram em (quase) nenhum 
relacionamento significante, exceto por conta de um Caligrama, que será apresentado no próximo tópico.

Outro exemplo de comportamento do modo Imagem como base apontado pelo autor é a abertura da série Vikings, 2013 (Figura 8), exibida no canal History Channel. O trabalho de Rama Allen, motion graphic designer do estúdio The Mill, nos EUA, é uma unidade independente que apresenta uma interpretação dos temas da série e não contém nenhum ator nem faz referência direta ao que aparece na produção. A imagem é evocativa do cenário histórico em que a série se passa e traz um efeito sutil que amplia o caráter alucinatório de uma descida às trevas. O conteúdo da série é realisticamente violento - o homem que se afoga é uma metáfora para a submersão na violência retratada na produção.

Figura 8: Frames da aberturada série Vikings, 2013. Fonte: YouTube

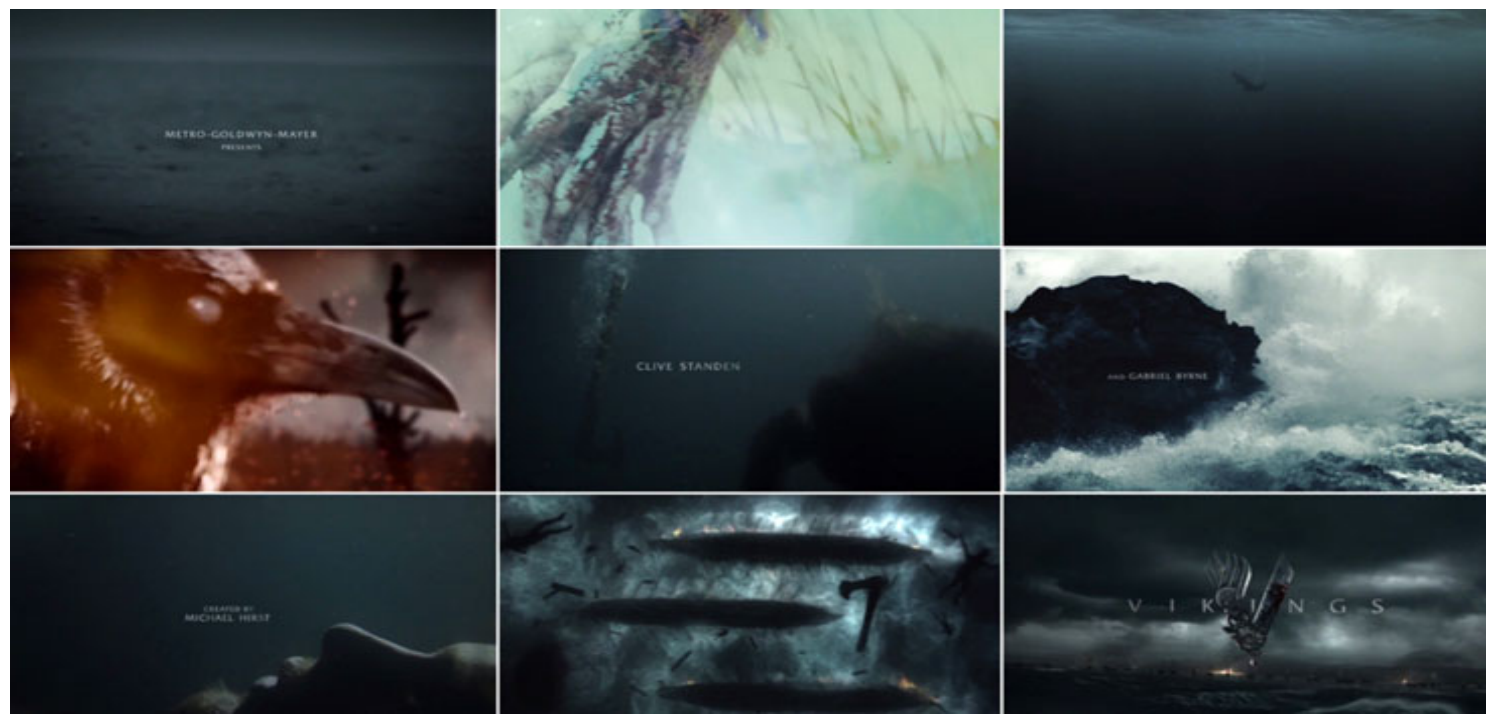

O modo Imagem como base é a relação mais simples entre texto e imagem - são colocados sobrepostos. O público reconhece a independência desses dois elementos enquanto o seu conjunto pode ser orquestrado para criar um novo arranjo estético. No entanto, eles são totalmente independentes. A complexidade ou sutileza do design reflete, assim, o arranjo desses domínios separados. Texto e imagem necessariamente convergem como o produto finalizado, mas no modo Imagem como base, a combinação é um fato técnico que deixa a imagem e o texto como articulações paralelas dentro de uma composição unificada. Quando começam a entrar em uma relação mútua como elementos justapostos e convergentes para produzir algum significado, ganha nova classificação: Caligrama ou Rébus, dependendo da natureza da conexão.

\section{O modo Caligrama}

Neste caso, o relacionamento do texto e da imagem depende de um reconhecimento por parte do público de uma conexão aparentemente direta entre eles. Esse "link" é fruto de uma estrutura formal que explora convenções já estabelecidas a partir de livros ilustrados de 
crianças: uma imagem de um objeto, como uma maçã, é acompanhada por um texto breve e declarativo sob a forma de uma legenda dizendo "maçã", identificando o objeto. Livros contendo caligramas são usados para ensinar a ler, com base na associação da imagem com palavras correspondentes.

No filme The Big Broadcast, 1937 (Figura 9), uma sequência de créditos faz uso extensivo de caligramas - os atores são todos identificados através por meio da conexão textos-imagens, acompanhados por uma narração que reforça a relação mostrada visualmente. O uso dos créditos coincide com o propósito deste filme em geral: apresentar estrelas de rádio, conhecidas pelo som de suas vozes, como estrelas de cinema. A ligação do caligrama dos atores aos seus nomes dá uma face (imagem) às vozes já familiares.

Figura 9: Frames do The Big Broadcast, 1937. Fonte: Michael Betancourt

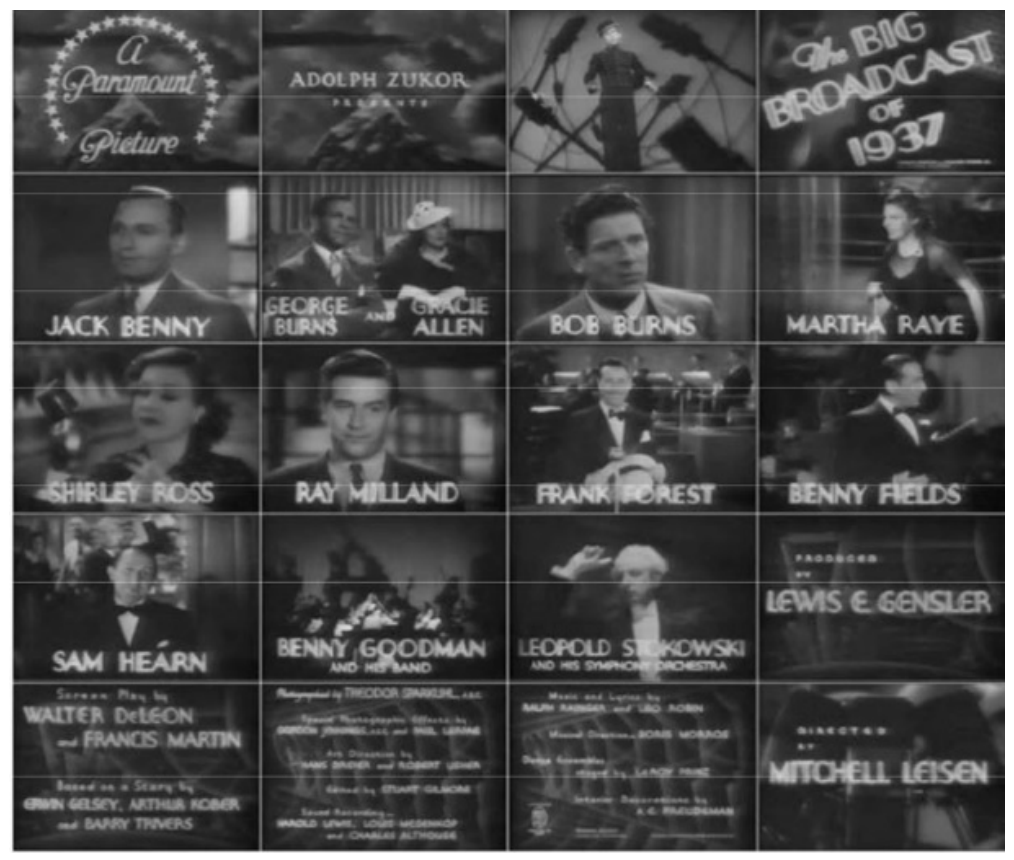

Voltando para o caso do filme Unknown (Desconhecido, 2011), especificamente para a sequência de Liam Neeson na janela de um avião que é acompanhada simultaneamente pelas palavras "Liam Neeson", uma ligação entre o texto e a imagem é imediatamente clara: Liam Neeson, o ator, aparece na tela e é rotulado pelo texto "Liam Neeson". Em Unknown, esta ligação é diferenciada do que ocorre em The Big Broadcast, por causa da fusão do crédito com a história dramática do filme. O personagem interpretado por Liam perde a memória e tenta provar sua identidade. Assim, o crédito ocupa uma posição especial porque uma parte dele é simultaneamente pertencente e ausente da narrativa.

Uma situação semelhante ocorre no filme Zelig, de 1983 (Figura 10). Quando a escritora Susan Sontag aparece, há um texto com seu nome e ela mesma se apresenta. O autor coloca neste caso o Caligrama no modo realismo documental. Sontag, fala com a câmera, não como uma interpretação em uma cena de maneira ficcional, mas num discurso para o público. 
Figura 10: Frame da abertura Zelig, 1983. Fonte: YouTube

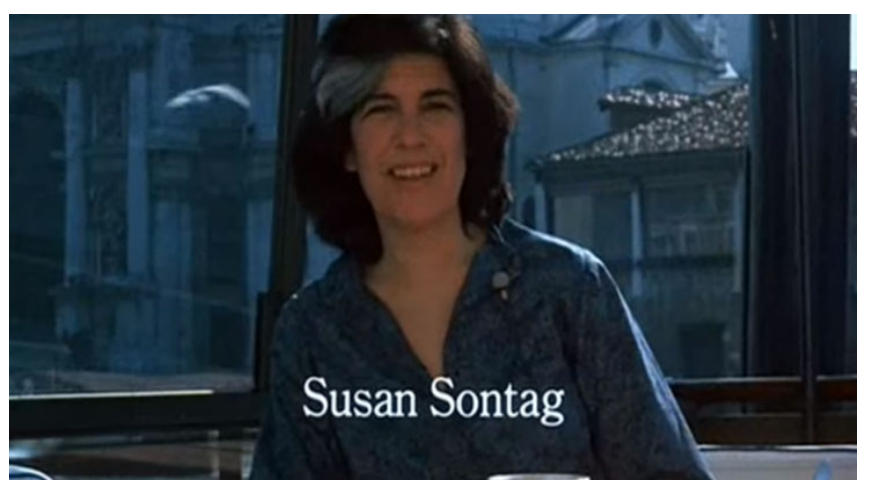

A diferença entre "Liam Neeson", os nomes das estrelas no The Big Broadcast e "Susan Sontag" não está ligada à organização do texto e da imagem apenas, mas na apresentação e consciência do público envolvido das particularidades destas produções.

\section{O modo Rébus}

Acontece quando uma imagem e um texto recriam novo significado, que não está explícito.

Este fenômeno depende de reconhecimentos distintos do público, originários de uma experiência passada e do conhecimento necessário para interpretar o que é exibido. Essa necessidade de um conhecimento pré-estabelecido produz o prazer estético dessas obras, que buscam pela interação entre os membros da audiência que reconhecem e entendem os relacionamentos apresentados.

Um exemplo de reconhecimento que depende de um público específico ocorre na abertura de The Good, the Bad and the Ugly (Três Homens em Conflito, 1966), feita pelo designer italiano Lardani (Figura 11). As imagens criadas por ele vêm de um trabalho preciso e cuidadoso em uma impressora ótica: os planos de fundo estáticos são feitos a partir de 'retenções' de imagens de ação ao vivo do próprio filme que foram impressas oticamente com um material de filme que acentua sua textura granulada, como o HiCon. Esses frames foram reprografados novamente com um filtro colorido para tingir a foto e compostos com outras máscaras HiCon feitas ao filmar uma pintura com pincel. Além da estética inovadora para a época, este trabalho contém um Rébus singular que aborda apenas uma pequena parte do público do filme: para o espectador inconsciente, este design simplesmente apresenta algo que estaria na categoria Imagem como base, mas para um público específico, que entende de impressão ótica, o Rébus é identificado. 
Figura 11: Frame com a assinatura de Lardani em The Bad, the Good and the Ugly, 1966. Fonte: YouTube

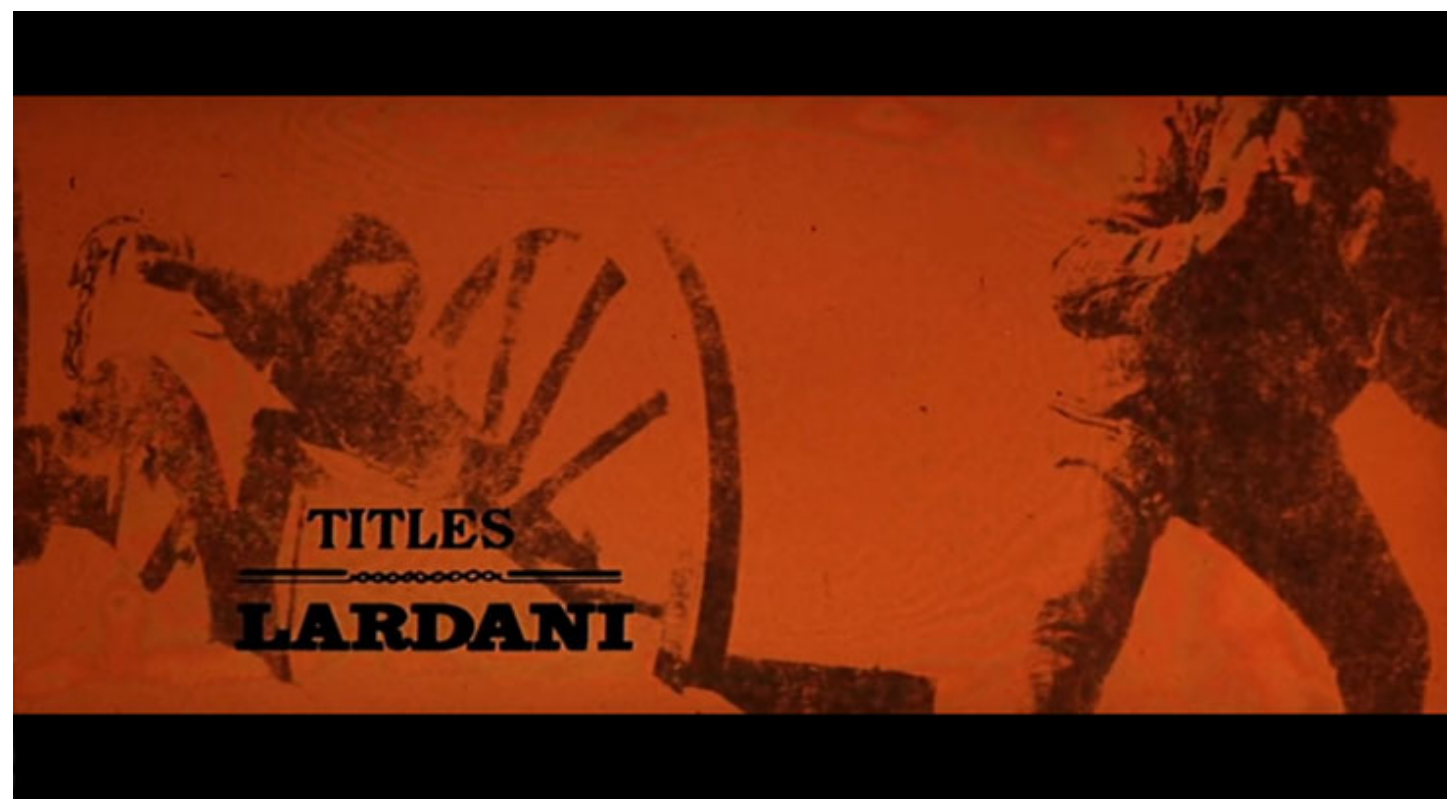

Há um "erro" específico de impressão causado pelo carregamento inadequado da gravação e da máscara Newton`s ring (Anéis de Newton). Justamente neste momento, Lardani assina seu trabalho: "TITLES - LARDANI." Considerando a perfeição técnica no resto da sequência, não é apenas um "erro de principiante", mas sim uma escolha consciente de incluir este erro de composição no design. Reconhecer o modo de recriação neste momento também requer a percepção das diferenças entre o crédito na tela e os outros créditos: a assinatura é mais curta, com pouco menos de 3 segundos, enquanto os outros créditos duram 5 segundos em média. $\mathrm{O}$ texto está em preto, em vez de branco, e a imagem escolhida para este title tem um caráter distintamente cômico em uma montagem dramática, até mesmo sombria, de atores e imagens de guerra civil.

Essa metáfora cômica do designer desatento é caracterizada ao vermos o personagem Tuco tapando os ouvidos e os olhos diante de um canhão. Em paralelo, é como se o autor da arte estivesse se preparando para os problemas que surgirão deste erro, compreensível (até mesmo reconhecível) por um público que entende o trabalho técnico envolvido.

Quando o público tem o conhecimento e a experiência para reconhecer e "desvendar" o Rébus (terceiro nível), ele navega facilmente entre o primeiro nível (Imagem como base) e o segundo nível (Caligrama). É um significado estritamente linguístico traduzido em forma visual, adiando sua conexão até que o público reconheça a relação entre o texto e a imagem associada.

Outro exemplo de Rébus está em To Kill a Mockingbird (O sol é para todos), de 1962 (Figura 12). No momento em que aparece o crédito "Screenplay by Horton Foote" um público mais atento deve reconhecer uma sequência de links entre um lápis de cor usado por crianças para desenhar e rabiscar palavras e o processo estruturado e cuidadosamente organizado de escrever um roteiro, que é o mesmo usado para "revelar" o título do filme logo aos 45 segundos 
(o trabalho dura cerca de 3 minutos). Ou seja, não é uma coincidência. Este texto e esta imagem não formam um Caligrama, e, sim um Rébus, porque o lápis simboliza o ato de adaptar o roteiro do livro ao filme.

Figura 12: Frame com o crédito de Horton Foote. Fonte: YouTube

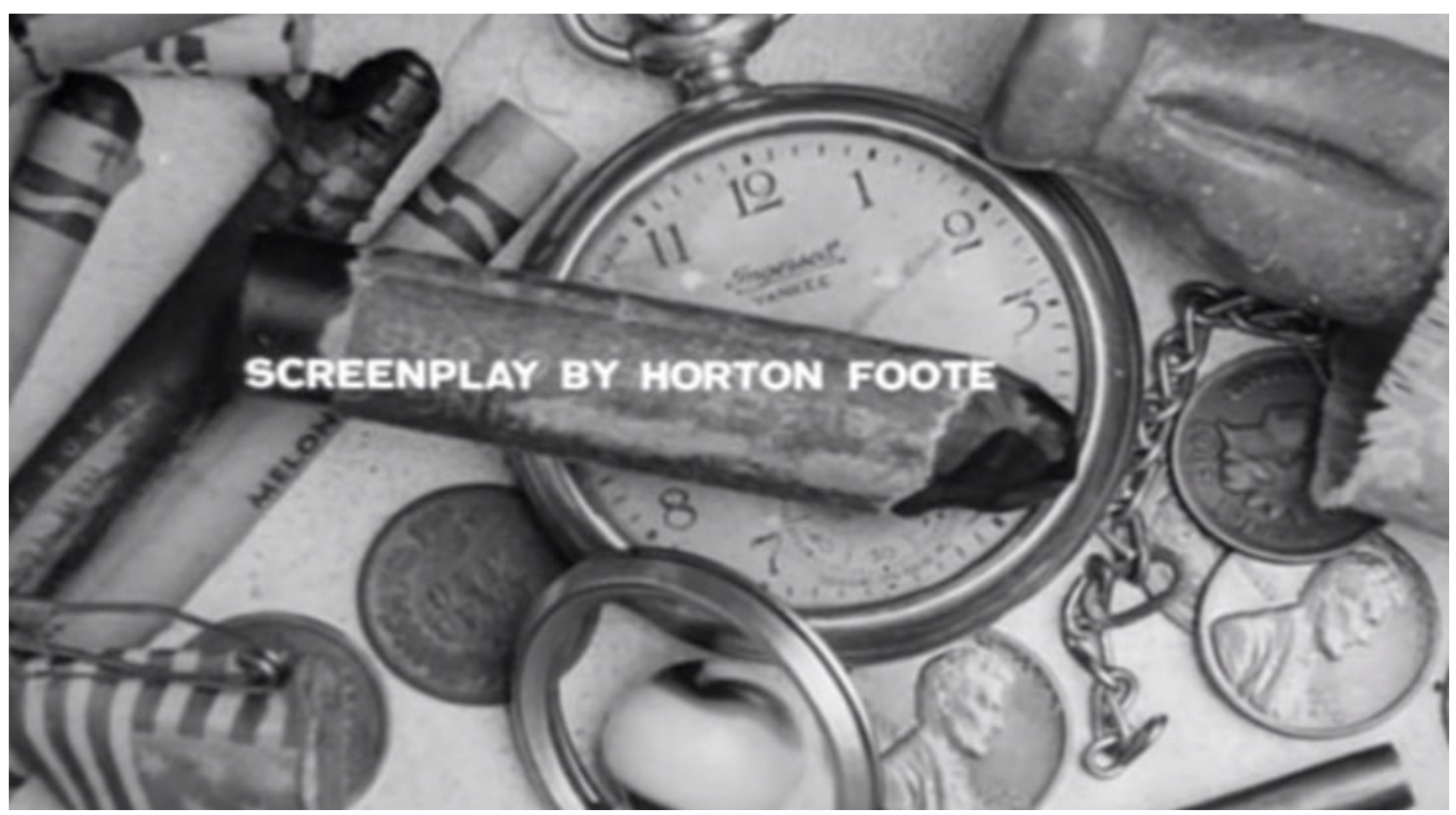

Essas transformações de conexões indiretas de imagem em texto via associação retórica modificam a relação fixa e controlada de contar uma história, com ocorre no modo Caligrama. A união do texto e da imagem no modo Caligrama produz uma duplicação ou reforço do mesmo significado, já o modo de Rébus transforma o que vemos em um significado que é diferente do que está representado.

\section{Considerações finais}

Este artigo, em uma resenha do autor referenciado, apresentou as possibilidades de interpretações que surgem da relação entre o texto e a imagem nas aberturas dos filmes. A teoria de classificação proposta por Michael Betancourt (2017), aponta os tipos mais comuns de conexões entre textos e imagens em trabalhos que acompanham filmes ou séries. As conexões indiretas entre imagem e texto via associação retórica modificam a relação de como vemos os créditos e resultam em outras histórias provenientes dos processos desenvolvidos pelos motion graphic designers. Para o autor, forçar a consideração de um significado, independente das imagens/textos, é uma deflexão do status representacional e de todo o contexto narrativo envolvido. E esse é um recurso explorado por designers desde o surgimento desta narrativa no cinema.

Acrescentamos o contexto histórico da elaboração de aberturas a essa análise, para que o resultado faça relação com o momento em que o trabalho foi exibido. Compreender o encontro 
do texto sobre a imagem nestas narrativas, conforme proposto por Michael Betancourt, é também entender que a sutileza está na técnica de composição visual que faz com que outras associações entre a história contada nas aberturas e os créditos surjam, revelando como os designers, em segundos de exibição, são autores de histórias independentes da produção ao qual seus trabalhos estão anexados.

\section{Referências}

Augusto, Sérgio. (2020). Saul Bass: o designer que aposentou a cortina dos cinemas. In Estadão. [Web page] Disponível em: https://alias.estadao.com.br/noticias/geral,saul-bass-odesigner-que-aposentou-as-cortinas-dos-cinemas, 70003303474

Betancourt, Michael. (2017). Semiotics and Title Sequences, Text-Image Composites in Motion Graphics. 1.ed. Ed. Routledge: Nova York.

Bicalho, Charles A. P. Saul Bass: uma anatomia do design de filmes. In: Revista do Audiovisual Sala 206, n 7, dez. 2017 - Universidade Federal do espírito Santo, Vitória, ES. https://periodicos.ufes.br/sala206

DesignPlusTitle. (2011, Agosto 29)., To kill a mockingbird title sequence. [Youtube]. Disponível em https://www.youtube.com/watch?v=LiqWpycexMs

Haskin, P .; BASS, S . (1996). 'Can you make a title?': Interview with Saul Bass. Film Quarterly, vol 50, pp. 10 - 17. Oakland: University of California Press.

Landekic, Lola. (2016, Fevereiro 23). Vikings. Art of the title. [Web page]. Disponível em: http://www.artofthetitle.com/title/vikings/

Leão, Gisela da Costa Lima. (2013). A Systemic Functional Approach to the Analysis of Animation in Film Opening Titles. Sydney.. [Tese de doutorado]. Philosophy Doctorate in Humanities and Social Sciences - University of Technology, Sydney.

Lupton, Ellen. (2020). O design como storytelling. GG editora: São Paulo.

MBA films. (2016, Setembro 08)., O Desconhecido filme completo dublado ação. [Youtube]. Disponível em https://www.youtube.com/watch?v=nK7y7qSRNzA

MovieTiles, Edil. (2012, Março 24)., The Good the Bad and the Ugly (1966) title sequence. [Youtube]. Disponivel em https://www.youtube.com/watch?v=kccafOf $4 \mathrm{O} 6 \mathrm{Q}$

MovieTiles, Edil. (2019, Março 26)., The Man with the Golden Arm (1955) title sequence. [Youtube]. Disponível em https://www.youtube.com/watch?v=PhwsLS1XolU

Rose, Gillian. (2016). Visual Methodologies: An introduction to the Interpretation of Visual Materials. Sage Publications: London.

Sales, Valdick. (2020, Julho 24)., Start - Revisão Sistemática de Literatura - Palestra no Zoom Vídeo 1. [Youtube]. Disponível em https://www.youtube.com/watch?v=UOkXmV206xg

Sarabia, Edil (2007, Março 20)., Zelig. [Youtube]. Disponível em https://www.youtube.com/watch?v=qUW8JsLDsNo

Shawn, Austin. (2019). Design for motion: Fundamentals and Techniques of motion design. 2.ed. Ed. Routledge: Nova York.

Skeater215 (2010, Agosto 20)., Mad Men parody HD. [Youtube]. Disponível em https://www.youtube.com/watch?v=193HrGxexXY 
Szafir, Milena. (2017). Design \& tele-audiovisualidades (ou, das formas videográficas) In: Intercom - Sociedade Brasileira de Estudos Interdisciplinares da Comunicação $40^{\circ}$ Congresso Brasileiro de Ciências da Comunicação, 04 a 09/09/2017 - Universidade Federal do Ceará, Fortaleza, CE. https://10.14591/aniki.v6n1.463

TV-Series-Opening Credits/Intro. (2017, Novembro 30)., Vikings : Season 5 - Opening Credits / Intro. [Youtube]. Disponível em https://www.youtube.com/watch?v=2xoh-aBr1mw

Williams, Natara. (2021, Março 07)., Castle: All Opening Title Sequence/Intros (Season 01 - 08) [HD]. . [Youtube]. Disponível em https://www.youtube.com/watch?v=KPaUZiBHYNQ

\section{Sobre os autores}

Jaíne Cintra, Me., UFPE, Brasil, <jainecintra@gmail.com>

Paulo Carneiro da Cunha Filho, Dr., UFPE, Brasil, <pauloccunha@gmail.com>

Marcelo M. Soares, Dr.,UFPE, Brasil <marcelo.soares@ufpe.br> 